\title{
DISASTER CIVILIAN DEFENSE IN URBAN MANAGEMENT BY PREPARATION OF EXECUTIONAL AND THINKING INFRASTRUCTURE
}

\author{
M. S. T. Tolou Del \\ Assistant Professor in Department of Architecture, Shahid Rajaee Teacher \\ Training University, Tehran, Iran
}

Published online: 15 May 2016

\begin{abstract}
To achieve a suitable environment in urban disaster management infrastructure should be anything before the intellectual and practical infrastructure management and above all it is made. Amenities and protect citizens with assistance in a timely manner is very important. The coordinating organizations working in disaster management cooperation is important. Establish ways of securing access to vital resources and intellectual life of the people is necessary. Food aid and medical supplies, and clothing, fuel, electricity and basic necessary equipment is also required. The most necessary work at all is providing the identity documents for the registration of personal details and property and cultural documents. In this study, we have tried to do everything necessary coordination in the event of natural disasters and specific categories to real risks to help people during natural disasters are better.
\end{abstract}

Keywords: Disaster; defense; urban management; execution and thinking infrastructure.

Author Correspondence, e-mail: msttd@ srttu.edu

doi: http://dx.doi.org/10.4314/jfas.v8i3s.183

\section{INTRODUCTION}

During 5,000 years of human civilization, about 15,000 historical wars occurred and almost 5 billion people in the world have been killed. If winter deterrent in fighting three wars and at least one event every year we've had natural killer worldwide. Around 200,000 people die 
each year in natural districts! Therefore, in the year 1200000 people in 40 districts of various mortal and abnormal disasters such as wars die.

\section{THE DEFINITIONS}

2.1. Defense: waste disposal and reduce the effects of destructive factors in the prevention of losses in equipment, facilities and vital community resources and prevent loss of human lives and to minimize the amount of damage.

2.2. Passive Defense: Facing the destructive elements through indirect actions and their lack of arms and efficient manner.

2.3. Urban management crisis violation: lacking social and failure to meet basic needs in natural disasters (humanitarian) non-natural (human).

\section{LITERATURE OF RESEARCH}

A new model for sustainable capacity building through civil-military collaboration is the Disaster Preparedness Program (DPP) that worked with the Embassy and other US government stakeholders to identify key ministance, a technical team from the partner nation undertook a comprehensive assessment of their current disaster response capabilities. This information was used to construct a disaster management strategic work plan that identified specific gaps in disaster preparedness. A disaster simulation exercise was conducted with representatives from agencies and ministries involved in disaster response. They applied their existing structure, plans and resources to a scenario designed for their country by CDHAM in order to identify any additional shortfalls in the plan. The finalized work plan could then be used by the partner nation to priorities and address immediate needs [1]. Orthopedic management in a a mega mass casualty situation is often necessity. Appropriate planning, operational versatility, and adjustment of therapeutic guidelines according to a constantly changing situation, enabled us to deliver optimal care to the maximal number of patients, in an overwhelming mass trauma situation [2].

Natural and traditional defense mechanisms to reduce climate risks in coastal zones of Bangladesh has showed that substantially resourceful and densely populated coastal zones of Bangladesh experience numerous extreme events linked to hydro-metrological processes vis. Cyclones, tidal surges, floods, salinity intrusion and erosion etc. These measures have been found to be impractical and ineffective in reducing disasters in coastal areas. There is a need for integration of traditional coping practices and wisdoms with modern approaches. Available knowledge on some of these traditional practices has been documented for 
establishing a sustainable policy for management of coastal zones of Bangladesh. By combining traditional and scientific management of coastal ecosystem with mangroves and other plants following triple-tier mechanism and habitat, it is possible to reduce the effects of natural and climate change-induced disasters. Under such a management system, the entire coastal zone can be made more productive and sustainable [3].

By improving Resilience against Urban Fire Hazards through Environmental Design in Dense Urban Areas in Surabaya, in Indonesia we have learned that paying attention to psychological safety, behavioral safety, defense for safety and safety against disaster in the design and planning of a neighborhood's paths, edges, nodes, districts and landmarks can improve disaster preparedness. A good environmental design can lower urban fire vulnerability, support mitigation efforts and increase disaster preparedness, and make a large difference in the response to an emergency situation. However, to improve overall resilience, both anthropogenic and bio-physic aspects that make up the environment must be acknowledged. Awareness against urban fires must be aged as the physical environment is shaped one component at a time [4]. In simplifying the Exploration of Cognplgx System Types, The analysis includes examination of a number of analysis categorization systems including recognizing the systems' autonomous and independent behavior, structural characteristics such as a central initiator of coordination, or a lack of one, Hitchens' level, complexity, both operational and cultural, development of mental models, exploration through systems dynamics, identification of leverage points, and consideration of Check land's soft systems approach [5].

For transferring functions of biological immune systems to communication processes in disasters we must using the cellular automata. The prototypical program simulates basic cascading disasters and provides findings regarding their development for different agent constellations. With the observations first practical implications are deduced for how to build up resilience in systems and to set up future research [6]. in the real-lime Compression System Research Based on Digital Micro-mirror Device Transform, (DMD) we would see as the programmable mask other than the conventional mechanical mask. This paper firstly introduces that the DMD spectrometer described in this paper is good at obtaining multichannel high-energy high-SNR spectral data, which is superior to traditional one of them [7]. By development and Use of a Comprehensive Humanitarian assessment tool in postearthquake in Haiti, has observed that $\mathrm{A}$ set of questions and data collection methodology were developed by a collaborative process involving a broad segment of the Haiti humanitarian relief community and used to conduct surveys in internally displaced person 
settlements and surrounding communities for a four-month period starting on 15 March 2010. Key considerations in the development of the assessment tool and data collection methodology, representative analysis results, and observations from the operational use of the tool for decision making are reported. Also concludes with lessons learned and recommendations for design and use of similar tools in the future [8].

To help people, handheld emergency logistics program for generating may be structured requests in Stressful Conditions because Effective response to such disasters requires rapid reaction and efficient, accurate processes. Since disasters often strike without any prior warning, rest responders have very little time to train and prepare for Humanitarian Assistance and Disaster Relief operations. These operations can span from several weeks to several months. This puts first responders in rather stressful conditions they may not be trained to handle the task they have to, fatigued, and working in rather rigid conditions [9].

To deflect or evacuate we must facing the hypervelocity asteroid impact disaster. Understanding of the near-Earth asteroid impact hazard has been evolving. As larger nearEarth OMBCIS (NEOS) are retired from concern by the space guard survey, as new search strategies oriented toward short-term warning are brought on line, as we Understand the increasing danger from NEOs in the $15 \mathrm{~m}$ to 40 in size range, in the aftermath of the 2013 Chelyabinsk impact disaster, attention necessarily must shift toward dealing with the most likely dangerous impacts, those in the range of Chelyabinsk to Tunguska [10]. Thus we have to analysis of tsunami culture in countries affected by recent tsunamis. Disaster preparedness and willingness of local populations to evacuate when the threat of these events arises. This paper will explore these cultural issues using as a basis questionnaires carried out by the authors during their own field visits to the last three major events (in Japan, Chile and Indonesia), and interpret these through the willingness of coastal communities to build protection measures along the shore and the impact that these can have on sustainable development [11].

Then by significance of vulnerability assessment in establishment of Hainan provincial disaster medical system, the regulatory role for vulnerability analysis/assessment has has been demonstrated in establishment of disaster medical system in various countries and or regions. In this a paper, we attempt to describe/propose how to adopt vulnerability assessment through mathematical modeling of major biophysical social vulnerability factors to establish an independent, scientific, efficient and comprehensive provincial disaster medical system in Hainan [12]. In addition, Hydrogeological hazards and weather events, as Triggering and evolution of shallow landslides we must consider on the complex nature of these instability 
events that affect anthropized areas does not allow specific approaches for the defense of single good, but it finds a more effective solution based on the extensive knowledge of territory, perhaps at the scale of individual or several watersheds [13].

In other the challenges of wild land fire management in all places, needs towards a community inclusive fire management approach. This approach has de-coupled fire management from land use and livelihoods that ironically rely on fire and account for most fire outbreaks, putting the country at high risk of fire disasters. This paper explored mechanisms for establishing a sustainable fire management approach in Botswana that is centered on land use fire needs. A fire management strategy that is based on the use of fire for land use management will be community inclusive. Where an appropriate institutional framework is provided, this approach will facilitate effective use of resources, integration of indigenous and modern knowledge systems and help re-focus fire management away from suppression [14]. Therefore Community-led disaster management in response to the Christchurch earthquakes as a framework for action would be considered. The discussion draws from research findings arising from two projects conducted by the Joint Centre of Disaster Research in partnership with resident Maori tribe that address Maori disaster-related concerns, including factors that facilitate community recovery. An overview of the Mãori emergency response. including perceived hindrances, is provided as background. Drawing upon frameworks provided within Actor-Network Theory cultural technologies that facilitate community well-being and recovery are identified and the ways in which technologies were operationalized within the emergency context outlined. With reference to the Hyogo framwork for Anion the applicabillty of integrating Mãori technologies into national civil defense emergency management policies is also discussed and recommendations are proposed for adapting and implementing these technologies as a component of integrated disaster risk reduction at the local, national and international levels [15].

Also we meet on the flood mitigation measures in the United Kingdom, the magnitude of the flood completely over whelmed existing flood defenses and made a mockery of well-known and packaged agendas meant to "prevent, protect and prepare" against such adverse occurrences. To look into various mitigating measures meant to overcome the lapses and inadequacies of the present system and to encourage a better informed approach in dealing with future occurrences. The paper will draw from existing documentation and legislation put in place to enhance corporate response, to avert repeating the cycle of flood disaster in the UK [16]. 
Then in the Rio-de-Janeiro Community Protection Program, With the goal of protecting the people living in those slums, especially the ones living in the risky areas, the Civil Defense of Rio de Janeiro has created the Community Protection Program focusing on three subjects: (i) Training of Local Agents, (ii) Community Alarm and Alert System, and (iii) Simulation exercises at public schools. Local Agents live and work in the community and their training is of a huge importance mainly because these residents know about the vulnerabilities and they are great multipliers, advising other people about the danger. The Simulation Exercises at public schools consists of training for the evacuation of the community in case of heavy rains. By risk monitoring in this case, the municipal civil defense has identified places which can temporarily shelter these residents in the period of heavy rains. Therefore, indoor courts, residents' associations, churches, schools and other establishments located at or near the communities, are the support points for receiving these residents. Several Simulated evacuation exercises have been organized to train and adapt, in a concrete way and as close to reality as possible, the residents of the areas at risk for their evacuation in an emergency situation. These trainings are also a great opportunity of exercising and evaluating the work of the people involved in the activation of sirens and opening of the support points, as well as stimulating the participation of volunteers and increasing the risk perception of the residents $[17,18]$.

So in Peru sustainable (resilient) cities program's application, we have the vision of during the Ica, Peru, 2007, earthquake, the actual damage distribution in Pisco, Tambo de Mora and other cities, agreed very well with the multi hazard map developed six years before, showing how useful those maps are [19]. Although at the last by evaluation of the System of disaster management resulting from war Operations and terrorism in Iraq, This research aims to show the significance of disaster and crisis "lallafiement in general. It also explores the current situation related to disaster response management in lraq.

This exploration focuses on the achievement of the basic functions of the management operation (planning, organizing, directing, controlling). In addition, it identifies the weaknesses and the strengths of the current administrative system in all its elements and analyses all the problems and the defects in every element, in order to treat and solve these problems and defects by making recommendations to improve the immediate response system to serve Iraqi disaster management in the future.

Finally, the study reached a set of conclusions and recommendations, including providing the directories of the civil defense with the heavy rescue equipment and providing specialist trained engineering staff to deal with the disasters and crises. Moreover, it sets in place an 
incentive scheme for the related members of the directories of the civil defense. Such schemes encourage them to continue working to face the unnatural circumstances that Iraq is experiencing and to create an environment similar to that of developed countries in the world. This contributes to overcoming the disasters of all shapes and reduces the damage to lives and property [20].

\section{STRATEGIES AND GOALS}

4.1. The overall objectives: prevention, warning, shelter construction, exposure, relief, deployment, support and rehabilitation

4.2. Defense purposes: cultural, social, political, economic, military, security, communications, intelligence, legal criteria, service and support

4.3. Work areas: 1. the area of theoretical and of software, 2.Practical field and objective hardware, 3.relative Logic ware

4.4. Thought out strategy: Minimum levels of damage, injuries to deal with the emergency, restore and maintain critical facilities, reducing the risk of developing collective sense of confidence, security and surveillance and coordination of crisis management to support

4.5. Practical solutions out: get to know and identify the causes, and the nobility of the time, pointing to the correct targets and measures, to stabilize the situation and improve conditions for performance, providing peace of mind by ensuring the physical, mental and spiritual people

4.6. Organizational features: 1 . Vital centers, sensitive, important and worthy of protection, 2. the preparation and performance verification centers (geographic, demographic, legacy), 3. Protection centers, security, relief, medical and rehabilitation centers 4. Determine the location, accommodation and access

\section{FUNDAMENTALS OF URBAN CRISIS MANAGEMENT}

5.1. Determine the needs and strategy documenting upstream

5.2. Determine priorities and needs and objectives of the Determine the general and detailed plans and implementation

5.3. Determining the consumption of resources and administrative support necessary

5.4. Resources (manpower, materials and eilulpmet used deputy)

5.5. In urban management (organizing, building, execution and supervision)

5.6. Performance evaluation and assessment to help determine patterns

The valuation process 


\section{THE PROCESS OF URBAN CRISIS MANAGEMENT}

6.1. Feasibility and risk assessment

6.2. Map design and planning work

6.3. Determining and implementing resources and complementary measures

6.4. Directing, supervision and assessment and evaluation

\section{THE GENERAL PRINCIPLES OF CIVIL CRISIS MANAGEMENT}

7.1. Identify cases and areas of crisis

7.2. Analysis and foresight, and the possibility of a crisis

7.3. Preparation and organization of resources and preparation processes

7.4. Integration and coordination of infrastructure activities

\section{PERSPECTIVES AND REQUIREMENTS}

\subsection{Prospects of passive defense}

Manifestation of national will, integration to popular belief, the institutionalization of social demand, structural empowerment, independence, accountability, territorial integrity, maintain national capital, motivation, interest in science and technology, in terms of convergence and integration, self-help and self-sufficiency and self-sufficiency both thinking and cooperation and coordination and consistency in the transactions relating to the defense of the city

8.2. The necessity of realization of passive defense:

The threat or risk of, the crisis of science (research, training, skills and readiness issue of quantity and quality in the face of threats)

8.3. Risk areas in passive defense:

8.3.1. Military (land, sea, air, space, and social and urban)

8.3.2. Economic background; (livestock, agriculture, garden, mineral, industrial and related services)

8.3.3. Social sector (health, education, financial, credit, and legal documents)

8.3.4. Security areas (nuclear, explosive, missile, chemical, biological and cyber)

8.3.5. Political context (organization, chaos, intelligence,disorderly and non-)

8.3.6. Natural background (path, faulting, stratigraphic, volcanic, sliding, freeze, frost, storms, pests, bacteria)

8.3.7. Infrastructure (equipment, facilities, access, communication and planning)

8.3.8. Management (organizational, components, features, limitations, Engineering and Legal) 


\section{STRATEGIC MODEL OF PASSIVE DEFENSE}

9.1. The idea of seeking to create administrative approaches

9.2. Determine the indicators and standards and criteria for planning

9.3. Forecasts priorities and needs of mental and

9.4. Determine the resources and capacity necessary documentation

9.5. Work programs and plans

\section{PROMOTE PASSIVE DEFENSE STRATEGIES}

10.1. The development of public expectations and establish monitoring of social goals and ideas (intellectual form)

10.2. Skills development and empowerment process and the development of new sources of new technologies (IT executive)

10.3. The development of social interaction and development expectations in providing appropriate environmental conditions to survive (on functional)

10.4. Formulation of legal and technical, administrative and regulatory procedures in the Community (the form and context form)

10.5. Create friendship and harmony, working in partnership and cooperation of all social (collective integration).

\section{ORGANIZATION STRUCTURE}

11.1. Organizational disaster management institutions:"

11.1.1. Staff of strategic planning and defining strategies for relief

11.1.2. Operational guidance and supervision and crisis management headquarters city

11.1.3. Headquarters inspection and evaluation of the implementation and preparation of maintenance organizations

11.1.4. Staff implemented the regional crisis of urban management objectives

11.1.5. Staff support and ancillary services to provide transport and accommodation necessary facilities and rehabilitation

11.2. Municipal organizations helping in crisis management:

11.2.1. International relief organizations Ministry of the Interior

11.2.2. Crisis prevention and in urban management of the municipality

11.2.3. Iran's Ministry of Defense and Armed Forces Logistics

11.2.4. Red Crescent Society of the Islamic Republic of Iran 
11.2.5. .Red Crescent youth and volunteers organized free

11.2.6. Doctors without Borders, Iran

11.2.7. Fire Department and Safety Services

11.3. Campaigns and queuing in crisis management:

11.3.1. Organizing, planning and coordinating the necessary common

11.3.2. Security working group executive, security and health security

11.3.3. Security service working groups, relief and support

11.3.4. Internal communication and create a hierarchy

11.3.5. The establishment of training and operational exercises for the Coordination

\section{STRATEGIC OBJECTIVES PASSIVE DEFENSE CRISIS}

12.1. Design of monitoring and management of physical and spiritual aspects of crisis

12.2. The preservation of human life and property from ritual and unnatural disasters and threats

12.3. Guarantee the continuity of essential activities of people after the crisis

12.4. The continuation of vital social needs (water, bread, food, energy, communications, health, security and shelter)

12.5. To facilitate the task of urban in urban management against natural hazards and unnatural

\section{AREA OF CIVIL DEFENSE OPERATIONS, DISASTER MANAGEMENT}

The media, information technology and specialized areas of technology, education, legal standards, rules and regulations, the in urban management Campaigns, the management of critical resources, health, identification of personal identity, property and the identification of physical and spiritual supports.

\section{VULNERABLE POSITIONS AND PRINCIPLES OF CIVIL CRISIS MANAGEMENT}

14.1. Urban vulnerable position in crisis:

14.1.1. Human resources (risky behavior, character, people, performance, management)

14.1.2. Building (demolished structures, gas, electricity and water tightness, fire, explosion and biological)

14.1.3. Facilities and equipment; (the vital, sensitive, dangerous, low-risk and periodicals)

14.1.4. Medical sources (vital, sensitive, critical, minor, rare, inherited) 
14.1.5. Shelters; (spaces dedicated secure, underground bunkers and shelters semi-buried)

14.2. City of passive defense in crisis management:

14.2.1. Concealing vital resources safe terrain and blind the enemy information system

14.2. 2. Camouflage and invisibility of vital resources and create color and compatibility environment

14.2.3. Production structures and parallel multi-scale systems depends on the optimal

14.2.4. Initiative to create a variety of performance measures and the creation of barriers to destructive factors

14.2.5. The proportion of the population and distribution or assembly of functional feasibility

14.2.6. Strengthening, retrofitting and upgrading public buildings and urban infrastructure

14.2.7. Agile, compact and affordable package of enforcement measures and the definition of alternative Crisis

14.2.8. Critical facility protection and safety at the same time distribution and dispersion performance and risks

\section{RULES AND PROVISIONS}

15.1. Explanation: definitions, concepts, areas of application, objectives, threats of buildings and urban infrastructure

15.2. Editor: grouping of buildings (in particular, important, important, moderate, or normal), normal load, normal and abnormal destructive

15.3. Zoning: urban development criteria (4 floors up is the accumulation of over 100 centers), architecture, structures, facilities and infrastructure

15.4. Physical considerations: Physical form fields of architecture, landscaping design and access, safe areas and shelters

15.4.1 Physical architecture (the volume of buildings, extensions, communications, safe, accessible and external walls and facades of buildings, openings and control of Windows, the blading and material, dimensions and width moving stairs and elevators

15.4.2 Infrastructure architecture (layout, entrances, access, open-walled shelter, the stairs area, steep roads)

15.4.3 Secure areas (layout, materials, internal organs, design requirements, communication infrastructure, and distribution capabilities, to achieve a secure environment)

15.4.4 Shelters (locating, grouping, (private, public, significance, function, length of time and capacity), technical specifications, entrances, container packing,- output and physical and psychological rehabilitationf,facilities) 
15.5. Technical considerations: consumer materials (mechanical properties and dynamical), the energy absorption capacity of the normal and abnormal destructive factors (shock, vibration, blast waves, hurricanes, accidents, etc.)

15.5.1 Diversity hazards (chemical, biological, nuclear, electromagnetic, graffiti, cyber, explosion, vibration, shock, turn)

15.5.2 Diversity of materials (concrete, reinforced masonry, stonework, viewing materials, construction steel, the coefficient of resistance, the coefficient of dynamic increase, the design yield strength of materials)

15.5.3 common structural variation (steel frame, reinforced masonry, reinforced concrete in situ, precast reinforced concrete, wood, composite and complex)

15.5.4 Shelter structural diversity (anti-explosion. anti-vibration, buried in situ, half buried in situ, buried prefabricated, pre-fabricated semi-buried)

15.6. Mechanical and electrical installations, technical requirements, scope, existing buildings, special installations, extensions, fixtures; (Ventilation, alf exchange, heating and cooling, sanitation, water supply, sewerage, gas, elevators, escalators, low power and high voltage, the electronics, signaling, telecommunications, communications, power, etc.)

Note: The capacity needs, emergency safe spaces should be considered so that at least 3 cubic meters of fresh air per hour per person provided.

\section{Conclusions and Solutions:}

16.1. To provide the theoretical and intellectual infrastructure, legal and procedural

16.2. Evaluation of the effectiveness of quality placing little capacity for crisis management centers

16.3. Assess the situation in terms of speed an ease of access to secure areas of the city

16.4. Organizational communications among disaster management authorities in cities

16.5. Providing training to security forces for crisis

16.6. Independent power facilities in time oi crisis centers

16.7. Fuel and gas, and self-sufficient, especially in crisis management centers

16.8. Facilities and replaced by fresh air from the air supply necessary

16.9. The possibility of food delivery and supply of essential medicines in the crisis headquarters

16.10. Assessment to identify and record personal and financial identity and personality 
16.11. The need to protect the lives and property of people and cultural heritage Electronic documents

16.12. Making access fast and efficient in providing service continuity and preparation equipment on matters relating to physical and mental health

\section{REFERENCES}

In addition on rules and experiences activities of Iranian Guidance Codes in this paper the below references have used

[1] G Oravec, C Beadling, "The Disaster Preparedness Program: a new model for sustainable capacity building through civil-military collaboration," www.thelancet.com/lancetgh,

[2] Oravec et al. Open Access article distributed under the terms of CC 8Y., Meeting Abstracts, and Published Online March 26, 2015.

[3] Elhanan Bar-On, Ehud Lebel, Yitshak Kreiss \& others, "Orthopedic management in a mega mass casualty situation,"Injury, int. J. Care injured 42 (2011) 1053-1059.

[4] Mohammed Ataur Rahman, Sowmen Rahman, "Natural and traditional defense mechanisms to reduce climate risks in coastal zones of Bangladesh," Weather and Climate Extremes 7 (84-95), 2015.

[5] Prananda Navitas, "lmproung Resilience against Urban Fire Halards through Environmental Design in Dense Urban Areas in Surabaya, Indonesia," Procedia-Social and Behavioral Sciences 135, (178-183), 2014.

[6] Vernon Ireland, "Exploration of Complex System Types,"

[7] Procedia Computer Science 20, (248 - 255), 2013.

[8] Peter Schmiedgen, Sebastian Wlesenhutter, iorg Rainer Noennig, 'Transferring functions of biologicalimmune systems to communication processes in disasters using cellular automata," Procedia Computer Science 35, (1333 - 1341), 2014.

[9] Xianyun Fan, Dingliang Hu, Zitian Li 8: others," Real-Time Compression System Research Based on DMD I-iadamard Transform Spectrometer,' Procedia Engineering 7, (297-303), 2010.

[10]M. A. Zissman, J. E. Evans, K. T. Holcomb \& others, "Development and Use of a comprehensive Humanitarian Assessment Tool in Post-Earthquake Haiti," Procedia Engineering 78, (10 -21), 2014. 
[11]Maj Ryan Barnes USMC, Capt Buck Bradley USMC, Gurminder Singh, Arijit Das," HELP: Handheld Emergency Logistics Program for Generating Structured Requests instressful Conditions," Procedia Engineering 78, (40 -48), 2014.

[12]Clark R. Chapman, 'Facing a Hyperveloclty Asteroid impact Disaster: To Deflect or Evacuate?" Procedia Engineering 103,(68-72), 2015.

[13] Miguel Esteban, Vana Tsimopoulou, Tomoya Shibayama at others, "Analysis of Tsunami Culture in Countries Aflected by Recent Tsunamis, 'Procedia Environmental Sciences 7, (693-702), 2013.

[14] Min Ll, Chuanzhu Lu, Wei Son 8 others, "significance of vulnerability assessment in establishment of Hainan provincial disaster medical system, ' Asian Pacific Journal of Tropical Medicine (590-596), 2011.

[15] Salvatore Monteleone, Maria Sabatino. "Hydrogeological hazards and weather events: Triggering and evolution of shallow landslides," international Soil and water Conservation Research, Vol. 2, No.2, pp.23-29, 2014.

[16] opha pauline Dube, "challenges of wildlandfire management in Botswana: Towards a community inclusive fire managament approach," weather and climate extremes 1, (p:2641), 2013.

[17]Christine M. kenney, suzanne phibbs, "community-led disaster management in response to theŌtautahi (christxhurch) earthquakes as a framework for action," international journal of disaster Risk reduction, 2014.

[18] Nquot, 1., kulatunga, U., "flood mitigation measures in the united kingdom, "procedia economics and finance 18, (81-87), 2014.

[19] marcio motta, marcelo abelheira, orlando gomes \& others, "Rio De Janeiro community protection program," procedia economics and finance 18, (128-135), 2014.

[20] Marcio Motta, Marcelo Abelheira, Orlando Gomes \& others, "Heavy Rains at Rio de Janeiro: Risk Monitoring," Procedia Economics and Finance 18, (157-164), 2014.

[21] Julio Kuroiwa, "Peru sustainable (resilient) cities programme 1998-2012. Its application 2014-2021," Procedia Economics and Finance 18, (408-415), 2014.

[22]Hajer Al-Dahash, Udayangani kulatunga, Dilanthi Amaratunga,"Evaluation of the System of Disaster Management Resulting from War operations and Terrorism in Iraq." Procedia Economics and Finance 18, (900-907), 2014. 
How to cite this article:

Tolou Del M. S. T. Disaster civilian defense in urban management by preparation of executional and thinking infrastructure. J. Fundam. Appl. Sci., 2016, 8(3S), 299-313. 